\title{
Exploring Relative Deprivation Theory with Social Identity Theory to Inequalities: Issue of Migrants in Biak, Papua
}

\author{
Novieta H Sari ${ }^{1,2 *}$ \\ ${ }^{1}$ Department of Human Geography, Newcastle University, UK \\ ${ }^{2}$ Department of Communication Studies, Universitas Nasional, Indonesia \\ *Corresponding author.Email: N.H.Sari1@newcastle.ac.uk or novietahsari@gmail.com
}

\begin{abstract}
Facing emerging-economic market, that shifting local culture to urban culture and civilisation. For some regions, such as Biak, Papua where the indigenous people still highly uphold the concepts of kinship and tribal. The diversity of human mobility and environmental change have emerged to resistance and negativity views in the perception, judgment and behaviour indigenous people, which shown both in social interactions and discursive. This occurs due to the lack of capacity and equity to compete with migrants, specifically with Javanese migrants. In this regard, this paper explores Relative Deprivation Theory with Social Identity Theory, to understand and get an insight to how people respond to dramatic changes from subjective-objective circumstances, to understand collective socio-cultural phenomena regarding migrants and inequalities.
\end{abstract}

Keywords: Migrant, Social Identity, Relative Deprivation Theory, Inequalities

\section{INTRODUCTION}

Javanese migrant in Biak is starting during World War II when Japanese came to Biak in April 1942, and bring workers from Java, because of human resources and capacity reasonings, to build three airfields in Biak. Namely Kornasoren Airfield (Yebrurro), Kamiri Airfield and Namber Airfield, that to be used as a strategic base for Japanese Naval Forces in the Pacific. However, the number of Javanese migrants increased significantly, due to Indonesian government transmigration policy in the early 1980 s, to reduce the overpopulation in Java [1]. A policy which due to its implementation, has largely taken the lands and jobs of Papuans, thus most of Papuans (Biaks) is referring as 'Javanisation'. The transformation that has shifted and eroded the existence of Papuan in culture, politics and social, until today is still highly likely influence Biaks' perception and behaviour towards Indonesian government, that expressed through the issues, such as referendum, customary land re-claims [2]. In addition, the attitudes and neglection are also shown by defying anything that is not rooted in Papua or Biak are a Javanisation.

Today, Biak-Numfor Regency has 139,171 residents and $69.89 \%$ of its population are considered to be indigenous members of the Biak-Numfor ethnic group and making Biak-Numfor ethnically less heterogeneous than elsewhere [3]. Although some assimilation does occur in Biak, such as marriage, and social conflict between Javanese migrants and indigenous people is barely in Biak. However, social interactions between indigenous people and migrants are generally still limited, and there are still wide socio-cultural distinctions and challenges. The latter predominantly arise because the high influx of migrants has reduced the proportion of native people in many areas, such as land, job, space, and equity. This may be due to discernible differences in terms of knowledge and economic capacity between native people and migrants.

The Biak-Papuans worry that their livelihoods and cultural survival is under threat. This has resulted in resentment among locals and prompted demands for 
independence from Indonesia [3]. Furthermore, inward migration has also enhanced competition among Papuans themselves, resulting in communal and tribal sentiment and conflict. As Widjojo [4] argues that "Rivalry also occurred among the Papuans themselves, inter-tribal competition among the Papuans can be observed between coastal and mountain people, and among communities of smaller traditional groups" [my translation]; for example, between Biaks and the Nabire people, or Saireri and Lapago Tribes.

Biak culture adheres to a kinship system which still plays an important role in daily life and interactions. This system profoundly shapes the prevailing body of knowledge and its references in Biak culture often intersect with the question of gender in relation to equality, justice, and the right to a voice, notably in the socio-political relationships between heads of tribes, communities, and migrants. As a result, "the native people of Biak-Papua are trapped in disempowerment structurally and culturally" [3].

This is made worse because of the long history of oppression in Papua, particularly during the 32 years of President Soeharto's rule characterised by the inequitable use of authority, law, policy and physical force to suppress freedom and equality. Such treatment in Biak, even when covert, has caused Biaks to face crippling discrimination. While this may not have directly affected everyone in society, it has resulted in endemic poverty, low levels of education, injustice, inequality and underdevelopment structurally and culturally to date [5].

\subsection{Biak: Sense of Place}

According to the Biak Statistics Agency (2016), the Regency has one of Indonesia's highest poverty rates and is considered to be amongst the fiscally weakest regions. As many as $27.44 \%$ of the population are defined as poor, which represents 37,530 residents of Biak living below the poverty line. The lack of development and welfare provision in Biak has long been associated with issues of inequality, injustice and human rights violations, particularly during the New Order period in 1966-1998, and levels of education are low amongst most of the population. This accompanies high unemployment rates in Biak, where over $50 \%$ of adults cannot secure sufficient employment to make a living [5].

In response to these issues, the Indonesian government granted special autonomy status to Papua, including Biak Regency, under Law No.21/2001, in an attempt to boost economic growth and development in the region. However, after two decades, this policy has still not overcome Papua (and Biak's) problems, including persistently high rates of poverty. Its sociopolitical issues of inequality and injustice issues stem from the social and economic gap between native Melanesian inhabitants and inward migrants (see chapter 4). Furthermore, Papua Biak's location at the eastern edge of Indonesia leaves it remote from the central government in Jakarta, thus leading to underdevelopment and a lack of infrastructure.

Although Papua Biak received Special Autonomy that makes this region accepted wider authorisation and more benefit than other regions, the result, especially in the economic growth in Papua Biak did not show any significant change than before. Poverty remains the main issues that occurred in Biak along with sociopolitical conflicts-injustice issues, -poverty ratio in Biak, Papua, compare to another province in Indonesia, the average poverty level in Indonesia's province, is $10,9 \%[5]$.

In relation to the issues discussed above, Biaks in this case live in a lack of 'economic' security and relative deprivation compared to other provinces in Indonesia, and particularly Java. This is not only due to leadership issues, such as the Regent having consistently failed (e.g., Biak's economic growth), but also relates with the cultural-political context in terms of how local people defined themselves in their social relations, practices and institutions, which inevitably influence native views to the presence of migrants.

Therefore, in order to explain people's unexpected interpretations of their objective circumstances to social justice, the study needs to be explored to reveal the nature of relative deprivation (RDT) with social identity (SIT). To do this, the study draws out socio-cultural variables relating to dominant traits, migration, cultural value-systems that form social identity of Biaks. This includes Biak's historical trajectories from colonialism to date. The aim is to explore and understand relative deprivation that has emerged to resistance and negativity views in the perceptions, judgments and behaviour of indigenous people, regarding migrants and inequalities. That is shown in differential pattern of collective responses of group to social justice [6].

\subsection{Relative Deprivation Theory (RDT)}

Smith and Pettigrew [6] define RD as "a judgement that one or one's ingroup is disadvantaged compared to a relevant referent, and that this judgement invokes feelings of anger, resentment, and entitlement (p.2)": referring to individuals and their reference groups. In this regard, there are four basic components that need to address to define individuals who experience RD. Namely, (1) first making a cognitive comparison, (2) then making a cognitive judgment that they or their ingroup was harmed, (3) feeling this loss as unfair, and finally (4) resenting this unfair and unjust loss. one of these four requirements is not met, the $\mathrm{RD}$ is not operating [6]. 
Related to the above, RD is a classic social psychological concept, used to catalyst wider social justice concerns, underlying psychological factors that are accounted to see relative deprivation as an outcome of social comparisons. It postulates subjective states that shape emotions, cognition, and behaviour. It links individual conditions to both interpersonal (Individual Relative Deprivation, IRD) and intergroup (In-Group Relative Deprivation, GRD) levels of analysis. It immerses with other social psychological processes, to challenges conventional wisdom about the importance of absolute deprivation. As Helsper [7] states "RDT is an evaluation of personal circumstances that depends on social and temporal contexts and are, therefore, relative (p. 223)". In this turn, to draw out the ideas of contextuality regarding social inequalities between native and migrants juxtaposed to the level of satisfactory to the government, the paper looks through an individual's ability and drive to overcome disadvantages, which is inevitably subjective rather than objective [7].

To do so, the empirical research documents in this paper are described in a range from collective action, prejudice, and felt grievance to political conservatism, perceived well-being and satisfaction with the government and policies gathered from the view that compare between oneself as a unique person and a referent (i.e., IRD), whereas GRD is the product of comparisons between one's ingroup and a referent. Also note the studies inevitably have the antecedents influenced by specific historical, cultural and experimental contexts (on some cases). Further away, basic of reaction in RD phenomenon is related to a sense of deservingness and entitlement in such as political beliefs, political protest, role of cultural, changes.

In this study, the focus is on specific social identity theory (SI) which closely relate to historical trajectory and cultural value systems in the place; the ways in which cultural shape RD reaction [6]. These include individualisation, and motivation constraints which lead to inequalities between social economic and cultural groups or deriving from individual micro individual level factors such as personality and skills ([8]; [7], p.224). In this way, we can argue that to locate the cause of inequalities within relative deprivation, as well as stopping short of reducing all deviant activity to individual volition and the negation of the social [9]. We need to allow for an appreciation of the ambiguities in people's reactions to different objective social position, as an approach.

In several studies of $\mathrm{RD}$, the emotional difference that revealed and prevailed in turn predicts numerous political attitudes and sociocultural phenomena - from collective action, prejudice, felt grievances, to political conservatism, perceived well-being and satisfaction with the government [6]. For example, Brandt et al. [10] RD study regarding the political beliefs of New Zealand's Maoris. The study shows that according to paradoxical evidence from members of disadvantaged groups, often support ideologies that undermine the group's collective interest. It then shows how the treatment of ideology as an outcome (as opposed to an antecedent or control variable) can reveal ways in which these beliefs could change. As Webber [9] argues that "the fluidity of deviant activity and, as such, connects to the contemporary concerns of cultural and social psychology (p.104)".

Grant et al. [11] also argues that in some classic RD social situations, such as race and class comparisons; skilled migrants and discrimination, both IRD and GRD are likely to be felt. Arguably, because both individuals or in-group are structurally caught in their reference groups, thus making them difficult to perceive circumstances and lead to grievances. Related to this, there is the critical role of angry resentment in the RD process that is likely compiled with social identity and collective efficacy, present a nuance understanding of political protests in past and future actions [11]. Interestingly, the extent to which this collective efficacy in the political protest actions, associated with their perceptions of their group's status as illegitimate and/or stable, and their identification within larger society, -in this case: Indonesian society [6].

Smith and Pettigrew [6] also add that respondent that give responses to open-ended questions relate the comparisons choice in RD research, for example race and class as comparisons. In some extent, implying the original political transition receded into the past, informed to other people by comparisons, from different classes, ethnic backgrounds, and other countries. To show the extent to which both individual and group grievances are important or less important.

\subsection{Social Identity: Migrants and Entitlements}

Identity, in terms of both individual and social, is performative, fluid, and dynamic. It is passed down over time through communities and families and its formation is influenced by various factors, including history, memory, place, and social structure and values [12]. Identity is widely believed to result from levels of social cohesion, reproduction and processes involving so-called 'structuring structures' tied to place [13] ; [14]; [15].

Therefore, to develop a comprehensive understanding of social identity, according to Capozza \& Brown [8], the assessment does not only explore cognitive behaviour and motivational processes within and between social groups. It also requires exploration to some degree of patterned behaviour and collective socio-cultural phenomena influenced by historical 
situations, in order to explain differential pattern (or varied array of phenomena) of collective responses of (inter)group that produce similar values and norms in perception, judgement and behaviour. That is, comparing responses from government agencies and indigenous people, regarding migrants and inequalities [6].

Some scholars argue that social identity can be used to describe (i) the self-structure of individuals, as they are defined by categorical memberships (Rosenberg \& Gara, 1985; Reid \& Deux, 1996); (ii) the character of intergroup relations [16]; or (iii) the relationship of the individual to the broader social structure (Breakwell, 1993) (cited in Deux, 2000, p.1). For this, social identity is assessed to acknowledge the forms of responses, where identities, intentions, claims, recognition, sovereignty, constitution, and paradigms collide and are implied predominantly for prospective gain, whether consciously or unconsciously ([17]; [18]; [19]). In this regard, the utterances that are constructed and displayed, as a meta-cultural attribute, are expressed to reflect who the person can and should be (identity), feeling (emotion), and how they can and should act (action), associated with their relating (social relations), and dwelling (living in place) ([20]; [21]).

To do so, data were collected from participants concerning their life experiences, historical events, and socio-cultural practices including systems, values and relationships that simultaneously produce social coherence and self-enhancement [8] The assessment is analysed to understand and interpret the meaning of the people's responds, -subjective-objective circumstances-, to capture social meanings that occur in its social ecology, such as the state, citizenship, social class, racial, ethnicity, gender or any other [22].

\section{METHOD}

Exploring relative deprivation theory (RDT) with social identity theory (SIT) is addressed as preference strategies to cope negativity views of in-group status position related to inequalities, because of human mobility [23]. For this purpose, the study examines historical situations in the place: Biak, Papua. Through SIT and RDT variables, the focus is to identify and explain differential pattern (or varied array of phenomena) of collective responses of (inter)group (i.e., how people respond to the (dramatic) changes in their objective circumstances), related to migrants and inequalities [6].

The study is based on empirical data collected through ethnographic observations and in-depth interviews with 20 participants conducted in 2018 and 2019 in Biak. The respondents varied from local government officials, village counsellors, community representatives to local people, both natives and migrants. The aim is to explore responses, in a sense of understanding socio-cultural phenomena, which inevitably bound up with the social context and norms of behaviour, their social identities that formed by modes of individualisation (i.e., reflectivity and perception); motivation; and social production (e.g., [24]; [25]; [26]).

The questions are not only of opinion or feeling, perception and reflection-, but also aspirations, objectives, and future expectations from their subjective-objective circumstances, with open-ended questions, the extent of which individual and group complaints are informed through comparisons with others from different classes, ethnic backgrounds, and other countries (Smith and Pettigrew, 2015). That is described in Individual Relative Deprivation (IRD) and Group Relative Deprivation (GRD) forms, to understand how both forms of RD relate to a variety of outcomes, such as from collective actions, political conservatism to satisfaction with the government. Also, the analysis will take enquiry further to construct core arguments about the relations of relative deprivation theory (RDT) and Social Identity Theory (SIT) ([27]; [28]).

\section{FINDINGS AND DISCUSSION}

My study is observing and interviewing a group of indigenous people who are structurally caught in a classic RD social situation. Because numerous migrants, Javanese in particular, who more knowledgeable and skilled in obtaining appropriate jobs in their chosen profession. Which many indigenous people encounter difficult in obtaining thus, they are likely to feel both IRD and GRD. There is anger and frustration about the perceived competition that many indigenous people perceive is highly unequal and difficult to deal with, because of the lack of knowledge and capacity, interestingly, was associated with (1) their perceptions of their group's status as illegitimate and/or stable and (2) their identification and perceptions of the group's position within the larger society, reflecting a nuanced understanding of political protest [6].

\section{1. Migrants, Policies and Biak's Social Justice}

"[T] he reason why economic growth fails in Biak is because of the increase in migrants in Biak. They took our jobs and our land, and the indigenous people are increasingly marginalised" (Interview data, 2018)

Native respondent who perceived highly unequal and difficulty to compete with migrants, due to lack of skills and personality differences which lead to inequalities between social economics, and cultural group. Not surprisingly, it explains why people are driven to do political protests. In a brief, if we look historical trajectory how the escalation of migrants 
escalation in Biak occurred, partly because of the government policy on transmigration during the reign of Presiden Soeharto back in 1980s. That is, Soeharto's policy of mass transmigration to Papua, including to Biak, in an effort to reduce overpopulation on the island of Java in the early 1980s, had caused many Papuans losing their land and livelihoods. As most Papuans say, Javanisation (Jawanisasi) has eroded their existence culturally, politically, and socially (Interview data, 2018). Given that there were 337,761 Javanese households between 1980-1984, and 750,150 more between 1984-1989 allocated in Papua (including Biak) for the programme of transmigration, which inevitably imposed Javanese roots to be induced and changed the local people's life and interactions, namely the roles and positions as indigenous people in social, economic, cultural and political terms locally and regionally [2].

One of the indigenous respondents pointed out that "Some Biak areas, including Moibaken village in Yendidori district and Son Sepse village in East Biak District, were seized by the Soeharto government to implement transmigration policies in the early $80 \mathrm{~s} \ldots$ houses were built, and plantation land was given to transmigrants from Java. But it didn't work then abandoned in the late 80 s to early 90 s, because the soil here is infertile (i.e. karst soils) ... " (Interviewed data, 2018). In addition, other actions which arguably also represent the grievance feeling and dissatisfaction of Biaks to the government, have also generated sentiment reactions toward both national Indonesian and local government. These include a re-claim to the customary lands, feelings of being marginalise due to socioeconomic disparities with 'Java' and migrants, to demands for Papuan independence.

Meanwhile, the narratives that have been inherited over time to believe that they lived better during the Dutch colonialism than when the Papuans were part of Indonesia is continuously provoked the Biaks. And that makes Biaks, who still have the legacy trauma because of human right issues tend to reject or neglect the plans and policies of the Indonesian government. For example, the special autonomy policy in 2001; the establishment of customary council in 2001, which they called a social engineering of the Indonesian government, because have the absence of a Papuan context or perspective and made socio-economic in Biak even worse (Interview data, 2018). Nevertheless, these conditions, conscious-unconsciously, has caused relative deprivation to Biak's people in well-being, security, and equality.

However, knowledge of Biak's felt to political conservatism, related to a sense of deservingness and entitlement in such as political beliefs, political protest, role of cultural and changes would not be complete without a sense of Biak's social structure and values. People in Papua generally, and Biak in particular, see culture and nature as essential components of their lives. This applies in their social-cultural systems too, including the leadership system, customary laws and social mores, which sometimes are difficult to reconcile with contemporary norms in development planning and to an extent have contributed to the lack of progress in Biak.

Socio-political identity in Biaks' perspectives, at some degree of political dogma, tends to make many Biaks to feel insecure and inequalities with other ethnics, social classes, cultures. As stated by this respondent: "[D]evelopment only happens in Java, not in Papua. This is because of the absence of a Papuan perspective in government development planning. And to do so, the government must involve Papuans [Biak's indigenous people] in its planning process, which they have not done ... To develop Biak, we need to foreground nature as our medium, because for indigenous people nature is a crucial medium. Besides nature, we also need to apply a religious approach [from Christianity] in development planning: hence, the government and religion must be able to be integrated" (Interview data, 2018)

Biaks, in this case, still live in the past, and thus are highly likely to ignore ideas of development as they exhibit distrust and dissatisfaction with their lack of security and relative deprivation compared to other provinces in Indonesia, and particularly Java. This is not only because of leadership issues, such as the Regent having consistently failed to develop Biak social economics. But it also because Biak's historical background and trajectory that shaped Biaks 'social identity' today that need taking into considerations, in order to understand $\mathrm{RD}$ rection that occurred in Biak (e.g., [29]; [30]; [31]).

In this turn, I argue the causes of social inequalities are seen as either coming from macro level structural constraints which lead to inequalities between social and cultural groups or deriving from individual micro individual level factors such as personality and skills. The grievances at both the individual and group levels, which analysed from inter- and intra-group comparative processes, in accordance with the present situation in Biak, arguably and contested, have put Biak's people feel more aggrieved than migrants at the individual level, whereas migrant respondents feel more aggrieved at the group level (GRD).

Finally, as the original political transition receded into the past, class-based comparisons gained in importance and ethnicity-based comparisons became slightly less important. In contrast, draws upon Biaks' responses to open-ended questions about their comparison's choices, from value expectation, legitimacy and capabilities between these two groups, native and migrants. The analyses show the extent to which both individual and group grievances are 
informed by comparisons to other people from different classes, ethnic backgrounds, and other countries, is highly likely a major concern for respondents.

\section{CONCLUSIONS}

In order to understand the issue of migrants and inequalities through RDT and IST, we need to allow for an appreciation of the ambiguities in people's reactions to different objective social position, as an approach. It represents value expectation, legitimacy and capabilities involved the emotional differences that is in turn can be used to predicts numerous political attitudes and sociocultural phenomena-from collective action, prejudice, felt grievances, to political conservatism, perceived well-being and satisfaction with the government [6]. It then shows how the treatment of ideology as an outcome (as opposed to an antecedent or control variable) can reveal ways in which these beliefs could change. For example, the claims of political beliefs, in this case, regarding migration and inequalities in social justice.

The importance of the social justice, however, is not underemphasised since the impact of inequalities on both parties, people and government, can lead to more permanent social problems. Social justice is not necessarily the most important issue to understand. Consequently, some of the celebratory discussion of social justice emanating from within the school of global development neglect the pain, tragedy and resentment of inequalities. Inequalities and deviancy are secondary to the process that led to action, be that act 'political protests' (however that is defined), fatalism or indeed empowerment. In other words, what this article is arguing for is an attempt to transcend the oftennarrow focus of social justice research and place inequalities and deviance within a broader social theory of practice. The reification of social justice/inequalities as the thing to be explained is a narrow focus indeed and excludes the wider contexts in which action takes places.

\section{REFERENCES}

[1] A. Ananta, D. R. W. W. Utami, and A. Purbowati, "Declining Dominance of an Ethnic Group in a Large Multi-ethnic Developing Country: The Case of the Javanese in Indonesia," Popul. Rev., vol. 55, no. 1, 2016, doi: 10.1353/prv.2016.0000.

[2] E. Rustadi and Junaidi, "Transmigrasi dan Pengembangan Wilayah,” 2011.

[3] A. Ananta, D. R. W. W. Utami, and N. B. Handayani, "Statistics on Ethnic Diversity in the Land of Papua, Indonesia," Asia Pacific Policy Stud., vol. 3, no. 3, pp. 458-474, Sep. 2016, doi: 10.1002/app5.143.
[4] M. S. Widjoyo, Papua Road Map: Negotiating the past, improving the present and securing the future, 2nd ed. Jakarta: KITLV, LIPI, and Yayasan Obor, 2010.

[5] Badan Pusat Statistik Biak, "Badan Pusat Statistik Biak tahun 2016," 2016.

[6] H. J. Smith and T. F. Pettigrew, "Advances in Relative Deprivation Theory and Research," Soc. Justice Res., vol. 28, no. 1, pp. 1-6, Mar. 2015, doi: 10.1007/s11211-014-0231-5.

[7] E. J. Helsper, "The Social Relativity of Digital Exclusion: Applying Relative Deprivation Theory to Digital Inequalities," Commun. Theory, vol. 27, no. 3, pp. 223-242, Aug. 2017, doi: $10.1111 /$ comt. 12110 .

[8] D. Capozza and R. Brown, Eds., Social Identity Processes: Trends in Theory and Research. London: SAGE Publications, 2000.

[9] C. Webber, "Revaluating relative deprivation theory," Theor. Criminol., vol. 11, no. 1, pp. 97-120, Feb. 2007, doi: $10.1177 / 1362480607072737$.

[10] M. J. Brandt, C. G. Sibley, and D. Osborne, "What Is Central to Political Belief System Networks?," Personal. Soc. Psychol. Bull., vol. 45, no. 9, pp. 1352-1364, Sep. 2019, doi: $10.1177 / 0146167218824354$.

[11] P. R. Grant, "The protest intentions of skilled immigrants with credentialing problems: A test of a model integrating relative deprivation theory with social identity theory," Br. J. Soc. Psychol., vol. 47, no. 4, pp. 687-705, Dec. 2008, doi: 10.1348/014466607X269829.

[12] P. Barron, Contesting Development: Participatory Projects and Local Conflict Dynamics in Indonesia. Yale: Yale University Press, 2011.

[13] R. Pain, "Social geography: participatory research," Prog. Hum. Geogr., vol. 28, no. 5, pp. 652-663, Oct. 2004, doi: $10.1191 / 0309132504 \mathrm{ph} 511 \mathrm{pr}$

[14] M. Grenfell, Pierre Bourdieu: Key concepts. Acumen Publishing Limited, 2010.

[15] A. Nayak, "Purging the nation: race, conviviality and embodied encounters in the lives of British Bangladeshi Muslim young women," Trans. Inst. Br. Geogr., vol. 42, no. 2, pp. 289-302, Jun. 2017, doi:

$10.1111 / \operatorname{tran} .12168$.

[16] H. Tajfel, Social Identity and Intergroup Relations. Cambridge: Cambridge University Press, 1982.

[17] E. Rooksby and J. Hillier, Eds., Habitus: A 
Sense of Place. United Kingdom: Ashgate, 2005.

[18] J. Goodwin, "Conceptions of Speech Acts in the Theory and Practice of Argumentation: A Case Study of a Debate About Advocating," Stud. Logic, Gramm. Rhetor., vol. 36, no. 1, pp. 7998, Mar. 2014, doi: 10.2478/slgr-2014-0003.

[19] R. Moran, The Exchange of Words, vol. 1. Oxford University Press, 2018.

[20] M. Scollo, "Cultural approaches to discourse analysis: A theoretical and methodological conversation with special focus on Donal Carbaugh's Cultural Discourse Theory," $J$. Multicult. Discourses, vol. 6, no. 1, pp. 1-32, Mar. 2011, doi: 10.1080/17447143.2010.536550.

[21] L. Alba-Juez, "Discourse Analysis and Pragmatics: Their Scope and Relation," Russ. J. Linguist., vol. 20, no. 4, pp. 43-55, 2016, doi: $10.22363 / 2312-9182-2016-20-4-43-55$.

[22] D. Farrugia, "Addressing the problem of reflexivity in theories of reflexive modernisation: Subjectivity and structural contradiction," J. Sociol., vol. 51, no. 4, pp. 872-886, Dec. 2015, doi: $10.1177 / 1440783313480396$.

[23] A. Mummendey, T. Kessler, A. Klink, and R. Mielke, "Strategies to cope with negative social identity: Predictions by social identity theory and relative deprivation theory.," J. Pers. Soc. Psychol., vol. 76, no. 2, pp. 229-245, 1999, doi: 10.1037/0022-3514.76.2.229.

[24] D. Layder, Social and Personal Identity: Understanding Yourself. London: SAGE Publications, 2004.

[25] W. Outhwaite, "Bourdieu and Habermas: 'Linguistic Exchange' versus 'Communicative Action'? A Reply to Simon Susen," Soc. Epistemol., vol. 27, no. 3-4, pp. 247-249, Oct. 2013, doi: 10.1080/02691728.2013.818734.

[26] B. Schiermer, "Weber's Alternative Theory of Action," Eur. J. Sociol., vol. 60, no. 2, pp. 239281, Aug. 2019, doi: 10.1017/S0003975619000109.

[27] L. Richards, Handling Qualitative Data: A Practical Guide, 2nd ed. London: SAGE Publications, 2009.

[28] H. H. AlYahmady and S. S. Al Abri, "Using Nvivo for Data Analysis in Qualitative Research," Int. Interdiscip. J. Educ., vol. 2, no. 2, pp. 181-186, Feb. 2013, doi: $10.12816 / 0002914$.

[29] S. M. Handley and C. M. Angst, "The impact of culture on the relationship between governance and opportunism in outsourcing relationships," Strateg. Manag. J., vol. 36, no. 9, pp. 14121434, Sep. 2015, doi: 10.1002/smj.2300.

[30] I. Morley, "Philippines Cities, Their History, Development, Culture, and Governance," J. Urban Hist., vol. 45, no. 5, pp. 1050-1056, Sep. 2019, doi: 10.1177/0096144218764405.

[31] J. Mbaye and C. Dinardi, "Ins and outs of the cultural polis: Informality, culture and governance in the global South," Urban Stud., vol. 56, no. 3, pp. 578-593, Feb. 2019, doi: 10.1177/0042098017744168. 